\title{
Immunoinformatics Comes of Age
}

\author{
Bette Korber*, Montiago LaBute, Karina Yusim
}

\section{ABSTRACT}

$\mathrm{W}$

ith the burgeoning immunological data in the scientific literature, scientists must increasingly rely on Internet resources to inform and enhance their work. Here we provide a brief overview of the adaptive immune response and summaries of immunoinformatics resources, emphasizing those with Web interfaces. These resources include searchable databases of epitopes and immune-related molecules, and analysis tools for T cell and B cell epitope prediction, vaccine design, and protein structure comparisons. There is an agreeable synergy between the growing collections in immune-related databases and the growing sophistication of analysis software; the databases provide the foundation for developing predictive computational tools, which in turn enable more rapid identification of immune responses to populate the databases. Collectively, these resources contribute to improved understanding of immune responses and escape, and evolution of pathogens under immune pressure. The public health implications are vast, including designing vaccines, understanding autoimmune diseases, and defining the correlates of immune protection.

\section{Introduction}

The adaptive immune response. The immune system is the body's defense against infectious organisms and other foreign agents. The first line of defense is innate immunity, rapid nonspecific responses that allow recognition of conserved signature structures present in many microorganisms, such as lipopolysaccharides in bacterial cell walls or proteins in flagella [1]. The second line of defense is the adaptive immune response, tailored to an individual threat. An infected host mounts an immune response specific to an infectious agent; after the infection is resolved, memory cells persist that enable a more rapid and potent response if the infectious agent is encountered again.

The adaptive immune response has two major arms: the cellular immune response of $\mathrm{T}$ lymphocytes, and the humoral immune response of antibody-secreting B lymphocytes. In both cases the immune response is stimulated by receptor recognition of a specific small part of an antigen known as an epitope. Antibodies generally recognize intact proteins. B cell epitopes can be linear, contiguous amino acids, or they can be discontinuous amino acids that are brought together spatially in folded proteins. Discontinuous epitopes are defined through mutagenesis, competition experiments, modeling, or through cocrystallization or modeling of protein structure and docking [2]. Even linear B cell epitopes are often conformation-dependent, and antibody-antigen interactions are improved when the epitope is displayed in the context of the folded protein.

In contrast, $\mathrm{T}$ cell epitopes are short linear peptides that are cleaved from antigenic proteins, although $\mathrm{T}$ cell epitope generation by protein splicing is also observed [3]. T cell epitopes are presented in the context of major histocompatibility complex (MHC) proteins, or, in case of humans, human leukocyte antigen (HLA) class I or class II molecules. Epitope presentation depends on both MHCpeptide binding and $\mathrm{T}$ cell receptor (TCR) interactions $[4,5]$. MHC proteins are highly polymorphic, and each binds to a limited set of peptides. Thus the particular combination of MHC alleles present in a host limits the range of potential epitopes recognized during an infection. The conformation of a T cell epitope embedded in an MHC protein is critical for TCR recognition [6,7].

Two fundamental types of $\mathrm{T}$ cells are distinguished by expression of CD8 and CD4 proteins, which dictate whether a $\mathrm{T}$ cell will recognize epitopes presented by class I or class II molecules, respectively. Underlying this high-level bifurcation is a complex array of other functional markers. A key effector function of $\mathrm{CD}^{+} \mathrm{T}$ cells is cytolytic activity resulting in apoptosis of virally infected cells [8], which depends upon the $\mathrm{CD}^{+} \mathrm{T}$ cell's previous exposure to antigen and activation state [9]. The primary function of $\mathrm{CD} 4^{+} \mathrm{T}$ cells is to produce cytokines that regulate the rest of the immune response. These functions are not exclusive, however $-\mathrm{CD} 4^{+} \mathrm{T}$ cells can induce cytolysis [10], and $\mathrm{CD} 8^{+} \mathrm{T}$ cells can secrete immunoregulatory factors.

$\mathrm{CD} 4^{+} \mathrm{T}$ cell epitopes are processed after encapsulation by antigen-presenting cells in membrane-bound vesicles, where they are degraded by proteases into the peptide fragments that bind to MHC class II proteins. Then they are delivered to the cell surface, where class II-peptide complexes can be recognized by the $\mathrm{CD} 4^{+}$TCRs [5]. In contrast, $\mathrm{CD} 8^{+} \mathrm{T}$ cells generally recognize viral or self antigens expressed from within a cell [11], proteins that are cleaved into short peptides in the cytosol by the immunoproteasome [12] at the Cterminal end of the peptide [13]. The $\mathrm{N}$ terminus is later trimmed by proteases in endoplasmic reticulum [14]. After cleavage, peptides are translocated by the transporter

Editor: Johanna McIntyre, National Center for Biotechnology Information, United States of America

Citation: Korber B, LaBute M, Yusim K (2006) Immunoinformatics comes of age. PLoS Comput Biol 2(6): e71. DOI: 10.1371/journal.pcbi.0020071

DOI: 10.1371/journal.pcbi.0020071

This is an open-access article distributed under the terms of the Creative Commons Public Domain declaration which stipulates that, once placed in the public domain, this work may be freely reproduced, distributed, transmitted, modified, built upon, or otherwise used by anyone for any lawful purpose.

Abbreviations: HLA, human leukocyte antigen; MHC, major histocompatibility complex; TAP, transporter associated with antigen processing; TCR, T cell receptor

Bette Korber, Montiago LaBute, and Karina Yusim are at the Theory Division, Los Alamos National Laboratory, Los Alamos, New Mexico, United States of America. Bette Korber is also at The Santa Fe Institute, Santa Fe, New Mexico, United States of America.

* To whom correspondence should be addressed. E-mail: btk@lanl.gov 
associated with antigen processing (TAP) into the endoplasmic reticulum for loading onto HLA class I molecules [12,15], although other transport pathways can be used [16]. The MHC class I-peptide complex is then presented on the cell surface, allowing recognition by epitope-specific TCRs on $\mathrm{CD}^{+} \mathrm{T}$ cells $[5,12]$.

Both B cell and T cell epitopes are constrained by sequence specificity, and mutations within and external to epitopes can result in immune escape. Obviously, mutations within an epitope can directly impact antibody-antigen interactions or epitope-MHC and TCR interactions. Mutations outside of the epitope can inhibit antibody binding through

conformational changes, or inhibit proper cleavage and processing of T cell epitopes $[17,18]$. TAP also binds peptides somewhat selectively [19]. While there is a predilection for certain peptides to be processed for MHC binding and presentation, processing steps must be general enough to accommodate a wide variety of potential epitopes so as to not excessively constrain $\mathrm{T}$ cell immunity.

Pathogen- and cancer-related immune responses are being characterized at a remarkable pace, with precise mapping of well-characterized epitopes and increasing use of full genetic typing of HLA-epitope presenting molecules,

characterization of accompanying crystal structures, and definitions of escape mutations. As these elements are defined piece-by-piece in the literature, it becomes increasingly valuable to assemble the data into searchable databases and to provide computational tools to assist in interpretation of this complex information. Defining epitope sequence specificity (including cleavage and transport signals and MHC binding) presents a tantalizing problem for computational biologists. The predictive amino acid patterns associated with these events are subtle, requiring sophisticated pattern recognition methods to infer directly from protein sequences which peptides have the potential to become epitopes. The complexity is compounded by the fact that recognition patterns might not be encoded by the contiguous primary sequence, but rather in local threedimensional structure. The response to this challenging problem has resulted in an abundance of Web-based methods enabling the exploration of immunologically relevant data from a variety of perspectives. This review summarizes a sampling of particularly useful and user-friendly Web-based computational tools and searchable databases. The computational methods and databases are described and referenced in the text, and Web links are provided in summary tables. As a cautionary note, the authors have not directly tested that the functions contained in these resources will produce meaningful results, nor have we done systematic comparisons of the output of the different analysis tools; users would benefit by reading the primary literature regarding the different analyses methods if they decide to use one or more in their own work.

Tools for predicting potential $\mathbf{T}$ cell epitopes in protein sequences. The most thoroughly studied step of T cell epitope generation is peptide binding to MHC molecules, and the Web-based databases that include peptide-MHC data enable binding predictions. The MHCPEP database [20], for example, contains 13,000 MHC-binding peptides. Each entry contains the peptide sequence, its MHC specificity and, when available, experimental methods, observed activity, binding affinity, source protein, anchor positions, and references.
This database, however, has been static since 1998. MHCBN [21] includes 18,790 MHC-binding peptides, 3,227 MHCnonbinding peptides, 1,053 TAP binders and nonbinders, and $6,548 \mathrm{~T}$ cell epitopes. A beta-version of the new Immune Epitope Database and Analysis Resource (IEDB) has recently come online that will focus on epitopes in potential bioterrorism agents or emerging infectious diseases [22]. More databases are available, and some are discussed below together with relevant prediction tools.

Peptide-MHC binding is the most predictable aspect of $\mathrm{T}$ cell epitope generation. MHC class I and class II genes are highly polymorphic, and the majority of their variable positions are located in binding pockets that restrict peptide interactions to those with particular amino acids at characteristic positions (Figure 1); the set of amino acids that are well tolerated in these binding pockets are called anchor motifs. The search for epitopes in full-length proteins or within the context of a reactive peptide can be narrowed through a search for MHC-appropriate anchor motifs. Primary HLA class I anchor positions are generally located at

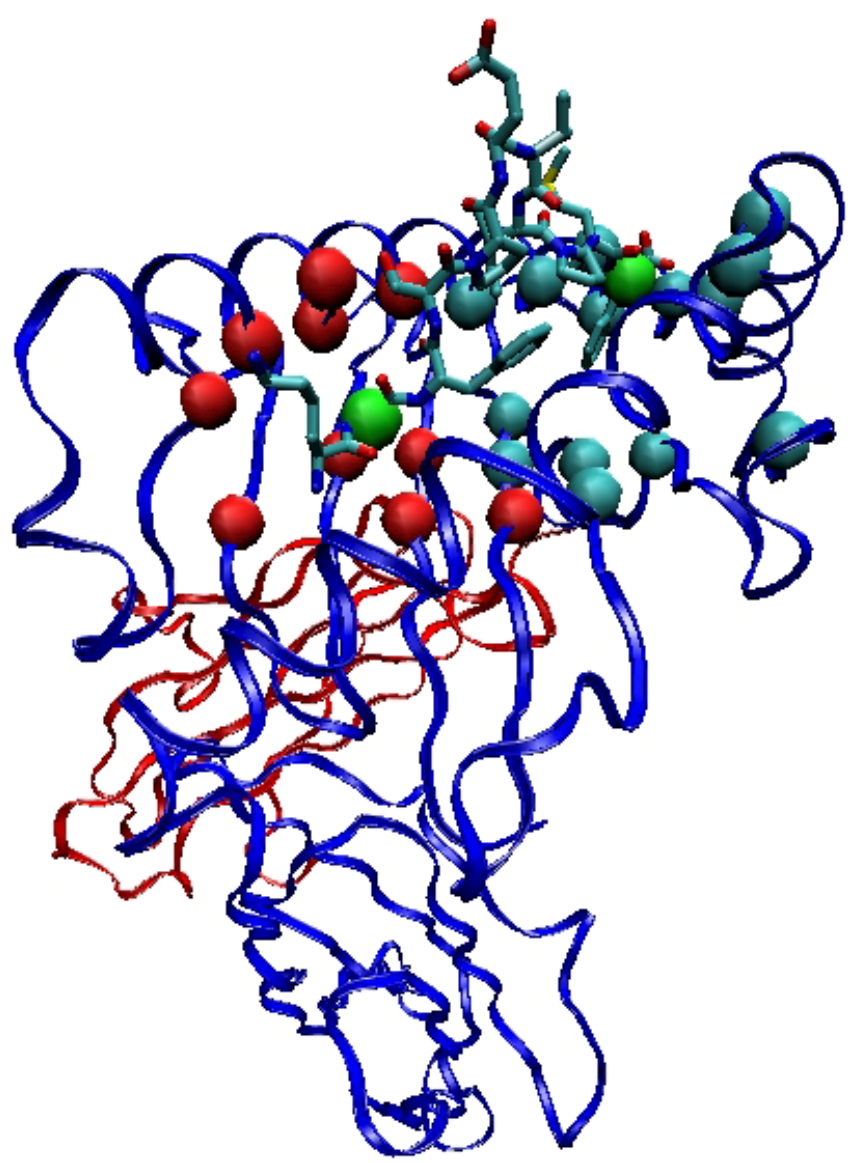

DOI: 10.1371/journal.pcbi.0020071.g001

Figure 1. Interaction of an Epitope with an MHC Class I Protein Ribbon representation of the $1.65 \AA$ resolution X-ray crystal structure of the MHC I allele $B^{*} 5703$ in complex with the KAF-11 peptide (KAFSPEVIPMF) derived from the HIV-1 p24 capsid protein. The blue ribbon indicates the alpha chain, the red chain is beta-2 microglobulin, and the molecule in the binding cleft is the antigenic peptide. The red and blue-green spheres mark the alpha carbons of the canonical peptide-binding B- and F-pocket residues, respectively. The green spheres represent the alpha carbons of the peptide anchor residues at P2 and P11. 
the $\mathrm{C}$ terminus and a middle position of a peptide; as optimal epitope lengths vary between 8 and 12 amino acids long, the spacing between these two positions varies [23,24]. The first MHC allele-specific motifs were defined for murine class II molecules [25]. Tracking anchor motifs patterns alone was soon found to be of limited predictive value [26], while including more extensive binding patterns using quantitative matrices representing the frequency and weight of every amino acid in every position enabled the prediction of epitope locations in protein sequences with somewhat greater [24,27-31], although still limited [32], accuracy.

For many MHC alleles, both simple and extended motifs are characterized and used to predict potential epitopes. For example, the SYFPEITHI database [33] contains extensive information on MHC class I and class II anchor motifs and binding specificity, and includes more than 4,500 entries of MHC proteins and aligned sequences of their epitopes and natural ligands, with source proteins, organisms, and publication references for each peptide. The SYFPEITHI epitope prediction server [33] uses a frequency-based scoring system for every amino acid position within a peptide. The SYFPEITHI database allows, through examination of aligned peptides known to bind the HLA molecules, appreciation of the relative level of conservation of anchor motifs, as well as the number of peptides that bind despite imperfect motifs

The Los Alamos HIV/HCV databases offer a simple tool (MotifScan) for identifying HLA anchor-binding motifs in query proteins, highlighting them on a protein or protein alignment [34,35]. This tool is based on motif libraries included at the SYFPEITHI site, assembled by S. Marsh and colleagues [23,24], and motifs extracted from the primary literature. The more sophisticated MHC-peptide binding prediction approaches have generally been applied to limited numbers of MHC proteins, so MotifScan provides a more comprehensive, but less reliable, exploration of potential HLA-binding peptides. The input protein sequences can be automatically uploaded from predefined sets of HIV or HCV proteins, or the user can input any protein sequence or sequence alignment. MotifScan is taken one step further for HIV and HCV through the Epitope Location Finder (ELF) [36], where HLA anchor motifs are mapped onto proteins or peptides in conjunction with known epitopes taken from extensive database listings of class I HIV and HCV T cell epitopes and their presenting HLAs [37,38]. Currently the HIV CD $8^{+}$T cell epitope database contains 3,150 entries describing 1,600 distinct MHC class I-epitope combinations (a single epitope can have multiple entries); the HCV database contains 510 entries describing 250 distinct MHC class I-epitope combinations. These databases include detailed biological information regarding the response to the epitope, including its impact on long term survival, common escape mutations, and whether an epitope is recognized in early infection; links to the primary literature; and curated alignments summarizing the epitope's global variability.

A central assumption of the traditional prediction methods based on motif frequencies is that each position contributes independently to binding. Interactions at one site, however, can affect interactions in another site [27,39]. Statistical classifiers such as Hidden Markov Models have better success rates at MHC-binding predictions, and machine learning methods such as artificial neural networks and support vector machines can recognize nonlinear sequence-dependent correlated effects in MHC binding. Machine learning methods as well as statistical methods are also useful for defining characteristic sequences related to TAP binding, and for addressing the complexity of proteasome cleavage [4047]. These methods, however, require large numbers of wellcharacterized peptides as training sets [32]. One comparative analysis suggested that motifs gave the most accurate MHCbinding predictions with limited data, but as the data increases, machine learning methods become more reliable predictors [48]. In another comparative study, a support vector machine outperformed other methods [40]. Both motif-based and machine learning methods for prediction of different steps of $\mathrm{T}$ cell epitope generation are available (Table 1) [49], often offered in combination with databases of MHC-ligand interactions (Table 2). Below we discuss some of the Web sites that are particularly helpful for T cell epitope prediction, many of which incorporate all three elements: immunoproteasome cleavage, TAP binding, and MHC binding.

The Edward Jenner Institute for Vaccine Research maintains the Antijen database, which contains quantitative experimental binding data for peptides that bind to $\mathrm{MHC}$, TAP, TCR-MHC complexes, T cell epitopes, and B cell epitopes; it also offers data on immunological proteinprotein interactions. It includes more than 24,000 entries. The MHCPred [50,51] tool predicts the energetics of proteinligand interactions related to the free energy of binding, and takes into account individual amino acids and contributions from side chain-side chain interactions, allowing peptideMHC and peptide-TAP binding predictions. This site also allows the prediction of high affinity peptides by comparing the predicted binding affinities of the original and the mutated peptides. PREDEPP [52,53] relies on the structural conservation and interactions observed in crystal structures of peptide-MHC complexes. A peptide's compatibility for binding is evaluated statistically by pairwise potentials. The Web site also predicts proteasomal cleavage sites [54].

The BIMAS tool $[31,55]$ ranks potential peptides based on a predicted half-time of disassociation from HLA class I molecules, based on coefficient tables deduced from the published literature. The Max Planck Institute for Infection Biology offers MAPPP software [56] that combines either BIMAS or SYFPEITHI MHC-binding prediction with the proteasome cleavage software FRAGPREDICT [57].

FRAGPREDICT predicts potential proteasomal cleavage sites based on a combination of two algorithms. A statistical analysis of cleavage-determining amino acid patterns is performed [57], followed by predictions of major proteolytic fragments based on a kinetic model of the $20 \mathrm{~S}$ proteasome describing the time-dependent digestion of smaller (up to 40 residues long) peptide substrates [58].

The following three suites of tools allow MHC/class I epitope prediction through a combination of cleavage prediction, TAP binding, and MHC binding. The Center for Biological Sequence Analysis offers the NetChop tool [44,59] for predicting proteasomal or immunoproteasomal cleavage using a nonlinear neural network, trained on in vitro experimental cleavage data or MHC class I ligand data, respectively. NetMHC [60-62] predicts binding of peptides to HLA supertypes (groups of HLA proteins that are likely to cross-present epitopes because of similarity in allowed binding motifs) or to 120 individual HLA alleles, using 
Table 1. Web-Based Interactive Tools for T Cell Epitope Prediction

\begin{tabular}{|c|c|c|c|}
\hline Database & URL & Summary of Output & Last Update ${ }^{a}$ \\
\hline BIMAS & http://thr.cit.nih.gov/molbio/hla_bind & Predicts HLA/peptide half time of disassociation & \\
\hline ELF & $\begin{array}{l}\text { http://www.hiv.lanl.gov/content/hiv-db/ } \\
\text { ELF/epitope_analyzer.html }\end{array}$ & $\begin{array}{l}\text { MotifScan summaries, integrating known epitopes and } \\
\text { HIV/HCV proteome epitope maps }\end{array}$ & 07 April 2006 \\
\hline EpiVax ${ }^{b}$ & http://www.epivax.comb & Prediction of class I and II conserved and promiscuous epitopes & \\
\hline CTLpred & http://www.imtech.res.in/raghava/ctlpred & $\begin{array}{l}\text { Prediction of CTL epitopes based on artificial neural networks } \\
\text { and support vector machines }\end{array}$ & \\
\hline FRAGPREDICT & $\begin{array}{l}\text { http://www.mpiib-berlin.mpg.de/MAPPP/ } \\
\text { cleavage.html }\end{array}$ & Prediction of proteasome cleavage sites & \\
\hline $\begin{array}{l}\text { IEDB Binding, } \\
\text { MHC Class I }\end{array}$ & $\begin{array}{l}\text { http://www.immuneepitope.org/analyze/ } \\
\text { html/mhc_binding.html }\end{array}$ & Prediction of class I-peptide binding using three different methods & \\
\hline $\begin{array}{l}\text { IEDB Binding, } \\
\text { MHC Class II }\end{array}$ & $\begin{array}{l}\text { http://www.immuneepitope.org/tools/ } \\
\text { matrix/iedb_input }\end{array}$ & Prediction of class II-peptide binding & \\
\hline IEDB Binding & $\begin{array}{l}\text { http://www.immuneepitope.org/analyze/ } \\
\text { html/mhc_processing.html }\end{array}$ & $\begin{array}{l}\mathrm{CD}^{+} \text {Tcell epitope prediction based on IEDB MHC class-I peptide binding } \\
\text { prediction, proteasomal/immunoproteasomal cleavage, TAP binding }\end{array}$ & \\
\hline iMAPPP & http://www.mpiib-berlin.mpg.de/MAPPP & $\begin{array}{l}\text { All predicted epitopes based on FRAGPREDICT and SYFPEITHI } \\
\text { or BIMAS and predicted MHC-peptide binding propensity }\end{array}$ & \\
\hline MHCPred & http://www.jenner.ac.uk/MHCPred & Predicted MHC/peptide or TAP/peptide IC50 binding values & 28 April 2005 \\
\hline MHC2Pred & http://www.imtech.res.in/raghava/mhc2pred & Prediction of promiscuous MHC class II binders & \\
\hline MMBPred & $\begin{array}{l}\text { http://www.imtech.res.in/raghava/ } \\
\text { mmbpred }\end{array}$ & $\begin{array}{l}\text { Prediction of promiscuous MHC class I binders and prediction } \\
\text { of mutations that will allow high affinity binding }\end{array}$ & \\
\hline MotifScan & $\begin{array}{l}\text { http://www.hiv.lanl.gov/content/ } \\
\text { immunology/motif_scan }\end{array}$ & Summary and location of anchor motifs & \\
\hline NetChop & http://www.cbs.dtu.dk/services/NetChop & Predicted proteasome or immunoproteasome cleavage & 05 January 2006 \\
\hline NetCTL & http://www.cbs.dtu.dk/services/NetCTL & $\begin{array}{l}\text { CTL/HLA-supertype epitope prediction, predicting NetMHC suptertype } \\
\text { binding, TAP binding, and NetChop proteasome cleavage scores }\end{array}$ & 05 January 2006 \\
\hline NetMHC & http://www.cbs.dtu.dk/services/NetMHC & Predicts MHC binding propensity of peptides & 09 August 2005 \\
\hline PAProC & http://www.uni-tuebingen.de/uni/kxi & Human and yeast proteasome, or immunoproteasome cleavage & 22 April 2005 \\
\hline Pcleavage & http://www.imtech.res.in/raghava/pcleavage & Predicted proteasome or immunoproteasome cleavage & \\
\hline PREDEPP & http://margalit.huji.ac.il & Predicted MHC-peptide binding based on structure & \\
\hline ProPred & http://www.imtech.res.in/raghava/propred & $\begin{array}{l}\text { Predicted MHC class II-peptide binding (there are other } \\
\text { related tools at the imtech Web site) }\end{array}$ & \\
\hline ProPred-I & http://www.imtech.res.in/raghava/propred1 & $\begin{array}{l}\text { Predicted MHC c lass I-peptide binding, optional proteasome/ } \\
\text { immunoproteasome cleavage filter }\end{array}$ & \\
\hline SYFPEITHI & http://www.syfpeithi.de & Predicted epitopes, binding motifs, epitope alignments for MHC proteins & \\
\hline TAPPred & http://www.imtech.res.in/raghava/tappred & Prediction of binding affinity of TAP proteins & \\
\hline TEPITOPE $^{b}$ & http://www.vaccinome.com & Prediction of promiscuous class II epitopes & \\
\hline
\end{tabular}

For the corresponding published references, please see the descriptions of the tools in the text. To use the imtech resources you must first register at: http://www.imtech.res.in/errors/ noauth.html.

aLast known update as of 02 May 2006. Empty cells indicate that updates were not readily available.

${ }^{\mathrm{b}}$ These tools do not have a Web-based interface, but access may be requested by contacting the design companies.

DOI: 10.1371/journal.pcbi.0020071.t001

artificial neural networks. NetCTL $[63,64]$ predicts epitopes by combining predictions of peptide-HLA-supertype binding (NetMHC), proteasomal C-terminal cleavage (NetChop), and TAP transport efficiency using a weight-matrix based method [65]. The Bioinformatics Centre Institute of Microbial Technology has also developed a suite of servers [21,40$42,66,67]$ designed for predicting immunologically interesting features in antigen sequences. ProPred 1 and ProPred, along with a series of related programs using different strategies, predicts specific MHC-binding peptides in proteins [67,68]. Promiscuous binders can be predicted using a support vector machine by MHC2Pred for MHC class II, or quantitative matrices by MMBPred for MHC class I [69]. Pcleavage uses a support vector machine to predict proteasomal cleavage based on in vitro data, or immunoproteasomal cleavage data based on MHC class I ligand data [42]. TAPPred predicts binding to TAP [41]. CTLpred predicts CTL epitopes in an antigen sequence by combining the processing and binding prediction methods [40]. IEDP also offers a suite of tools for T cell epitope prediction. Their peptide-MHC class I binding prediction tool allows the options of using an artificial neural net, average relative binding [70], or a stabilized matrix method [71]. A comparison of the accuracy of these methods is underway by the IEDP team. These three methods also use the average binding method for the prediction of MHC class II peptide binding [70]. Their MHC class I-peptide binding prediction can be combined with immunoproteasome cleavage [72] and TAP transport predictions [65], to predict MHC class I epitopes.

Many of the sites listed are convenient for large-scale calculations. Some, for example SYFPEITHI and MHCPred, allow one to incorporate multiple HLA alleles for epitope prediction, while others, such as NetChop, NetMHC, NetCTL, FRAGPREDICT, and IEDP tools allow one to upload protein alignments. MotifScan, MAPPP, and the ProPred series allow both. These methods are currently being applied to peptide vaccine design and can be used to identify epitopes that have the desirable properties of promiscuous presentation by many HLAs and relative conservation [69,73,74]. We have recently taken a very different approach to $T$ cell vaccine design and developed a computational method for designing polyvalent protein cocktails that provide maximum peptide 
Table 2. T Cell-Related Immunological Databases and Tables

\begin{tabular}{|c|c|c|c|}
\hline Database & URL & Summary of Output & Last Update ${ }^{a}$ \\
\hline $\begin{array}{l}\text { Allele } \\
\text { Frequencies }\end{array}$ & http://www.allelefrequencies.net & $\begin{array}{l}\text { HLA frequencies in worldwide populations and } \\
\text { polymorphism frequencies in immunologically. } \\
\text { Important alleles like KIR and different cytokines }\end{array}$ & \\
\hline AntiJen & http://www.jenner.ac.uk/antijen & $\begin{array}{l}\text { Quantitative binding data for MHC-ligand interactions, } \\
\text { TCR-MHC complexes, TAP }\end{array}$ & \\
\hline $\mathrm{dbMHC}$ & http://www.ncbi.nlm.nih.gov/projects/mhc & HLA alignments and tools for typing & \\
\hline $\begin{array}{l}\text { dbMHC } \\
\text { Anthropology }\end{array}$ & $\begin{array}{l}\text { http://www.ncbi.nlm.nih.gov/projects/mhc/ } \\
\text { ihwg.cgi?ID }=9 \& \mathrm{cmd}=\text { PRJOV }\end{array}$ & $\begin{array}{l}\text { HLA anthropology database with many populations represented } \\
\text { by genetic typing, and quick views of HLA frequencies }\end{array}$ & \\
\hline HIV Immunology & http://www.hiv.lanl.gov/immunology & $\mathrm{CD}^{+}$and $\mathrm{CD}^{+}{ }^{+} \mathrm{T}$ cell HIV epitopes, proteome epitope maps & 01 May 2006 \\
\hline HCV Immunology & http://hcv.lanl.gov/immuno/ & $\mathrm{CD}^{+}$and $\mathrm{CD}^{+}{ }^{+} \mathrm{T}$ cell $\mathrm{HCV}$ epitopes, proteome epitope maps & 20 April 2006 \\
\hline IEDB & http://epitope2.immuneepitope.org/home.do & Beta-version of biothreat pathogen T cell epitope database & Beta release February 2006 \\
\hline IMGT/HLA & http://www.ebi.ac.uk/imgt/hla/allele.html & $\begin{array}{l}\text { Aligned and annotated HLA sequences following the } \\
\text { World Health Organization nomenclature }\end{array}$ & 06 April 2006 \\
\hline IMGT/TR & http://imgt.cines.fr/textes/IMGTrepertoire & Aligned and annotated T cell receptor sequences & 23 September 2004 \\
\hline MHCBN & http://www.imtech.res.in/raghava/mhcbn & $\begin{array}{l}\text { MHC-peptide binders and nonbinders, TAP-peptide } \\
\text { binders and nonbinders, T cell epitopes }\end{array}$ & \\
\hline $\begin{array}{l}\text { MHC Haplotype } \\
\text { Project }\end{array}$ & http://www.sanger.ac.uk/HGP/Chr6/MHC & $\begin{array}{l}\text { The haplotype of MHC-linked-diseases, with complete } \\
\text { genomic sequences, variations (SNPs and DIPs) and } \\
\text { ancestral relationships. }\end{array}$ & 15 February 2006 \\
\hline MHCPEP & http://wehih.wehi.edu.au/mhcpep & MHC-presented epitopes & June 1998 \\
\hline MotifScan & $\begin{array}{l}\text { http://www.hiv.lanl.gov/content/ } \\
\text { immunology/motif_scan }\end{array}$ & $\begin{array}{l}\text { Genotype/serotype/supertype conversion tables } \\
\text { HLA-specific primary anchor motifs }\end{array}$ & \\
\hline PDB & http://http://www.rcsb.org/pdb/Welcome.do & $\begin{array}{l}\text { Structural database and viewing tools, MHC/peptide/ } \\
\text { TCR combinations }\end{array}$ & 02 May 2006 \\
\hline SYFPEITHI & http://www.syfpeithi.de & MHC-presented epitopes, MHC-specific anchor and auxiliary motifs & \\
\hline
\end{tabular}

For citations and summaries, see text.

aLast known update as of 02 May 2006. Empty cells indicate that updates were not readily available.

DOI: 10.1371/journal.pcbi.0020071.t002

coverage (where peptides are set to a user-specified length, for example nine amino acids) in a population of diverse proteins [75]. The mosaic proteins we create resemble real proteins, as they are assembled using a genetic algorithm by in silico homologous recombination of natural strains, and sets of mosaics are created based on the optimizing their combined population coverage. While no Web interface has yet been built for this code, the two related programs are freely available. One program enables an exploration of the peptide coverage in any set of natural proteins by a prototype vaccine strain or combinations of strains, while the other designs sets of mosaic proteins for a polyvalent vaccine that will maximize population coverage. These tools could be applied to any variable pathogen for vaccine design, or used to design sets of reagents to probe the immune response.

HLA-related databases and Web services. The number of genetically defined MHC and HLA alleles continues to expand, with a corresponding evolving and expanding nomenclature. The European Bioinformatics Institute maintains the IMGT/HLA sequence database [76], which includes HLA allele listings as defined in the World Health Organization Nomenclature Committee Reports. The reports include previous designations, accession numbers, references, and information on the source of the allele. This Web site has sequences and alignments from HLA class I and II loci, from the related MICA and MICB loci and from TAP1 and TAP2. To find Protein Data Bank (PDB) structures of MHC alleles in complex with peptides and/or the TCR domain, one easy method is to perform a BLAST search using the MHC alpha chain on PDB itself. There are about 100 available structures of MHCs in complex with peptides (mostly A alleles for MHC class I), and 20 of MHC, peptide, and TCR complexes (mostly involving HLA A2-related alleles).

The National Center for Biotechnology Information (NCBI) maintains dbMHC [77], which includes summaries of the genetic organization of the HLA region, genetic sequence alignments, and tools for HLA typing. It also houses the HLA anthropology database, where individual allele and haplotype frequencies can be retrieved from many different populations, nations, or geographic areas. The Allele Frequencies in Worldwide Populations project also offers summaries of HLA frequencies, as well as polymorphisms in cytokines and KIR alleles. The Sanger MHC haplotype project offers information on MHC related disease haplotypes, sequences, polymorphisms, and ancestral relationships [78,79].

Tools to assist the experimental $\mathrm{T}$ cell immunologist. Experimental $\mathrm{T}$ cell response mapping efforts recently have been scaling up, including additions of variant peptides to better probe responses to variable pathogens and extensions of $\mathrm{T}$ cell response mapping studies to span the full proteome of pathogens for large study populations (for one example of a population study incorporating Elisot mapping of T cell responses to HIV, see [80]). Complete datasets for several of these large T cell peptide response studies for HIV are available (http://www.hiv.lanl.gov/content/immunology/hlatem/index. html). These efforts have led the HIV/HCV database team to develop computational tools to facilitate study design and analyses of experimental data of this nature. These tools could, for the most part, be applied to any pathogen or protein. PeptGen [81] enables a user to design overlapping peptide sets of any length and overlap, using a single sequence or an alignment if a variable pathogen is being studied and peptide 
variants are desired. If an alignment is used, insertions or deletions in the sequence are handled sensibly, and a ready-forordering peptide list is created, organized so that identical peptides between need only be ordered once. If a population with known HLA typing is screened, for example by EliSpot, Hepitope allows a rapid search for HLAs that are enriched among people that react with each peptide in the study, and provides anchor motif searches for the enriched HLAs. For HIV- or HCV-related studies, ELF [36] can be combined with Hepitope to map previously described $\mathrm{CD} 8^{+} \mathrm{T}$ cell epitopes onto a reactive peptide.

There is growing interest in defining and comparing HLA allele frequencies in study populations where vaccine trials are planned; thus we have made a suite of tools to compare HLA frequencies in two populations, to identify alleles in linkage disequilibrium, and to fill in estimates of missing HLA information if full genetic typing is not feasible (Note: we will add a URL if the beta-version is ready in time, and delete this section otherwise). Because of the high cost of genetic HLA typing, although it is desirable, the reality is that often only partial HLA genetic typing of key alleles is available. A partially described data set could provide the basis for informed guesses of the HLA genotypes superimposed onto two-digit typing-for example, by utilizing available fourdigit data genetic typing data at dbMHC for different populations or a cohort subset that is fully genetically typed. Thus we have created a computational tool in which fourdigit HLA allele designations are estimated from a combination of two-digit and four-digit HLA typing data. A maximum likelihood probability is assigned to each four-digit estimate, based on a combination of allele frequencies in the population and linkage disequilibrium patterns.

Tools for predicting B cell epitopes and related Internet resources. The conformational aspects of antibody binding complicates the problem of $\mathrm{B}$ cell epitope prediction, making it less tractable than $\mathrm{T}$ cell epitope prediction. Indeed, Blythe and Flower [82] recently undertook an exhaustive assessment of amino acid propensity scales using the AntiJen B cell epitope database, and even the best combinations performed only marginally better than random [83]. If one wishes to explore antigenic propensity using traditional methods, however, IEDB provides tools for predicting five features that have been proposed to relate to B cell antigenicity, including beta turn prediction [84], surface accessibility [85], flexibility [86], and hydrophilicity [87]; it also includes an antigenicity predictor based on amino acid frequencies in antigenic domains and chemistry [88]. An alternative strategy for predicting linear B cell epitopes, ABCpred, uses a neural network trained and tested on the BCIPEP B cell epitope database [66].

Although antibody epitope prediction is difficult, many other antibody-specific resources are available on the Web (Table 3). If the variable region sequence of a monoclonal antibody is obtained, ABcheck [89] enables a rapid crosscheck against the Kabat antibody database to identify unusual residues that might be a sequencing artifact. (As a historical aside, the Kabat database was an early immunological database compiled to provide researchers with a comprehensive comparison of antibody sequences. It was available as a book long before the Internet enabled Websearchable molecular databases, at a time when GenBank, a resource that originated at Los Alamos National Laboratory, was still in its early, groundbreaking stages. GenBank eventually moved to the National Library of Medicine. Similarly, the Los Alamos HIV database, the first pathogenspecific sequence database, was initially available only as a book of aligned viral sequences.) The sequence could then be submitted to DNAPLOT, alignment software that enables rearranged $\mathrm{V}$ genes to be reliably assigned to their closest $\mathrm{V}$, $\mathrm{D}$, and J segment germline counterparts. The most comprehensive data for crystallographic structures can be found at the molecular modeling database (MMDB) [90], summaries of antibody crystal structures are maintained at SACS [91], and both structures and alignments are available through the antibody group (ABG). The ImMunoGeneTics (IMGT) database provides annotated listings and alignments of both immunoglobulins and TCR binding regions [92,93] .

We maintain comprehensive Web-searchable databases of pathogen-specific HIV [37] and HCV antibodies [38]. These are listings of monoclonal and polyclonal responses to the proteomes of these pathogens, including information regarding epitope location and variation, escape mutations, structure, biological impact of antibody responses, keywords, and links to PubMed. The HIV database currently contains 1,273, and the HCV database 120, unique antibody entries. Antibody entries are associated with multiple publications; for some of the more intensively studied HIV neutralizing monoclonal antibodies, more than 130 papers are cited, each with a brief summary of what was learned about the specific antibody in that paper. It is difficult to track a given monoclonal antibody in the literature by other means, as often many antibodies are used in a single study so are not named in an abstract. To compound the problem, the name of a monoclonal antibody often "mutates" as it is exchanged between different labs, so is not readily searchable by traditional means.

\section{Discussion}

This review is intended as a portal to some of the most useful online immunological software and searchable databases. This is a rapidly expanding area-experimental advances have moved immunology into population-based studies and simultaneously have brought us to the brink of comprehensively characterizing an individual's immune response to infection. Extensive listings of $\mathrm{T}$ cell epitopes and HLA-binding peptides, as well as peptides that do not bind, have been an invaluable resource for motif resolution and epitope prediction. Epitope prediction in turn facilitates detection of new epitopes, vaccine design, site-directed mutagenesis (to make proteins less immunogenic), potential autoantigen identification, and the design of immune-based cancer therapies. Given the compelling nature of the problem and its suitability for computational methods, many scientists have developed interesting alternative approaches to epitope prediction in silico, and have made their methods freely available through the Web (Table 1). We applaud this effort, but have the nagging concern that as the number of epitopes defined after an initial computational prediction prescreening grows, the resulting sets of experimentally defined epitopes may bias subsequent predictors in ways that traditional protein scanning with overlapping peptides would not.

Promiscuous HLA presentation and epitope prediction offers one sensible strategy for the creation of $\mathrm{T}$ cell vaccines 
Table 3. B Cell/Antibody-Related Databases and Analysis Tools

\begin{tabular}{|c|c|c|c|}
\hline Database & URL & Summary of Output & Last Update ${ }^{a}$ \\
\hline ABcheck & http://www.bioinf.org.uk/abs/seqtest.html & $\begin{array}{l}\text { Alignment of new antibody sequences against the } \\
\text { Kabat database to identify sequencing errors }\end{array}$ & 12 April 2006 \\
\hline ABCpred & http://www.imtech.res.in/raghava/abcpred/ & Artificial neural net linear B cell epitope predictor & \\
\hline $\mathrm{ABG}$ & $\begin{array}{l}\text { http://www.ibt.unam.mx/vir/structure/ } \\
\text { structures.html }\end{array}$ & Directory of antibody structures and sequence alignments & February 2006 \\
\hline AntiJen & http://www.jenner.ac.uk/antijen/ & Quantitative binding data for B cell epitopes & \\
\hline BCIPEP & http://www.imtech.res.in/raghava/bcipep & B cell epitope database & \\
\hline DNAPLOT & http://vbase.mrc-cpe.cam.ac.uk & $\begin{array}{l}\text { Align the nucleotide sequence of a rearranged } \mathrm{V} \text { gene to } \\
\text { the closet } \mathrm{V}, \mathrm{D} \text {, and J segment germline counterparts }\end{array}$ & 24 February 2005 \\
\hline IEDB & http://epitope2.immuneepitope.org/home.do & Beta-version of biothreat pathogen B cell epitope database & Beta release February 2006 \\
\hline $\begin{array}{l}\text { IEDB Ab Epitope } \\
\text { Prediction }\end{array}$ & $\begin{array}{l}\text { http://www.immuneepitope.org/tools/ } \\
\text { bcell/iedb_input }\end{array}$ & $\begin{array}{l}\text { Calculates antigenic propensity scores based on } \\
\text { amino acid properties }\end{array}$ & \\
\hline IMGT/IG & http://imgt.cines.fr/cgi-bin/IMGTlect.jv & Immunoglobulin structures and annotated sequences & \\
\hline HaptenDB & $\begin{array}{l}\text { http://www.imtech.res.in/raghava/ } \\
\text { haptendb/ }\end{array}$ & $\begin{array}{l}\text { A listing of haptens, structural similarity searches, } \\
\text { and antibody and biological information }\end{array}$ & \\
\hline HIV Immunology & http://www.hiv.lanl.gov/immunology & $\begin{array}{l}\text { B cell HIV epitopes, pathogen proteome linear epitope } \\
\text { maps, extensive literature citations regarding monoclonal } \\
\text { antibodies, curated epitope alignments }\end{array}$ & 01 May 2006 \\
\hline HCV Immunology & http://hcv.lanl.gov/immuno/ & $\begin{array}{l}\text { B cell HCV epitopes, pathogen proteome linear epitope } \\
\text { maps, extensive literature citations regarding monoclonal } \\
\text { antibodies, curated epitope alignments }\end{array}$ & 15 April 2006 \\
\hline MMDB & $\begin{array}{l}\text { http://www.ncbi.nlm.nih.gov/entrez/ } \\
\text { query.fcgi?db=Structure }\end{array}$ & $\begin{array}{l}\text { The most comprehensive listing of crystal structures } \\
\text { available, including antibodies and HLA, and TCRs }\end{array}$ & \\
\hline SACS & http://www.bioinf.org.uk/abs/sacs & Summary of antibody structures & 15 August 2005 \\
\hline
\end{tabular}

For citations and summaries, see text.

a Last known update as of 02 May 2006. Empty cells indicate that updates were not readily available.

DOI: 10.1371/journal.pcbi.0020071.t003

[69,73,74]. Alternatively, a rational epitope-informed peptide vaccine design can utilize the data in specialized pathogenspecific databases to focus on epitopes with the most biological promise to be beneficial [94]. Finally, for a highly variable pathogen, we are trying approaches intended to improve the coverage of potential epitopes in the population, for example by using a single consensus or ancestral sequence [95-97] or a computationally designed polyvalent vaccine that will maximize epitope coverage [75].

Understanding the impact of host immune-pathogen interactions on pathogen evolution, pathogenesis, and immunogen design depends on coordinated global efforts to gather and share data and requires the combined expertise of experimental and computational scientists. Only through this type of cooperation will we fully harvest the knowledge implicit in the data. The computational tools presented here are not yet ready to supplant experiment, rather they should assist in experimental design and interpretation of data. We clearly do not know all of the rules yet, for instance in peptide-MHC binding, and key questions such as what determines immunodominance in $\mathrm{T}$ and $\mathrm{B}$ cell responses are still unanswered. Yet the range and power of the tools already available through the Internet, many representing global networks and collaboration, is a testimony to the substantial progress we have made in facing emerging infectious diseases and potential biothreats with broader and deeper collective knowledge.

\section{Supporting Information}

\section{Accession Numbers}

The Protein Data Bank (http://www.rcsb.org/pdb) accession number of HIV-1 p24 capsid protein is $2 \mathrm{BVO}$.

\section{Acknowledgments}

We thank Thomas Leitner, Jennifer Macke, and James Theiler for their useful suggestions regarding the manuscript. We sincerely apologize for any tools we have missed in this summary; the Web is vast, and we covered what we could.

Author contributions. BK, ML, and KY wrote the paper.

Funding. The NIH/NIAID provides funding for our pathogen databases at Los Alamos through the interagency joint NIH/DOE agreement Y1-A1-1500-08 (BK and KY). The Los Alamos National Laboratory has provided us with internal funding for computational tool development for immunological studies and vaccine design.

Competing interests. The authors have declared that no competing interests exist.

\section{References}

1. Eckmann L (2006) Sensor molecules in intestinal innate immunity against bacterial infections. Curr Opin Gastroenterol 22: 95-101.

2. Saphire EO, Parren PW, Pantophlet R, Zwick MB, Morris GM, et al. (2001) Crystal structure of a neutralizing human IGG against HIV-1: A template for vaccine design. Science 293: 1155-1159.

3. Hanada K, Yewdell JW, Yang JC (2004) Immune recognition of a human renal cancer antigen through post-translational protein splicing. Nature 427: 252-256.

4. Janeway CA, Travers P, Walport M, Shlomchik M (2005) Immunobiology. New York: Garland Science Publishing. 600 p.

5. Rudolph MG, Stanfield RL, Wilson IA (2006) How TCRs bind MHCs, peptides, and coreceptors. Annu Rev Immunol 24: 419-466.

6. Maenaka K, Jones EY (1999) MHC superfamily structure and the immune system. Curr Opin Struct Biol 9: 745-753.

7. Messaoudi I, LeMaoult J, Metzner BM, Miley MJ, Fremont DH, et al. (2001) Functional evidence that conserved TCR CDR alpha 3 loop docking governs the cross-recognition of closely related peptide:class I complexes. J Immunol 167: 836-843.

8. Kagi D, Ledermann B, Burki K, Seiler P, Odermatt B, et al. (1994) Cytotoxicity mediated by $\mathrm{T}$ cells and natural killer cells is greatly impaired in perforin-deficient mice. Nature 369: 31-37.

9. Wolint P, Betts MR, Koup RA, Oxenius A (2004) Immediate cytotoxicity but not degranulation distinguishes effector and memory subsets of CD8 ${ }^{+} \mathrm{T}$ cells. J Exp Med 199: 925-936. 
10. Hammond SA, Obah E, Stanhope P, Monell CR, Strand M, et al. (1991) Characterization of a conserved T cell epitope in HIV-1 gp 41 recognized by vaccine-induced human cytolytic T cells. J Immunol 146: 1470-1477.

11. Matsumura M, Fremont DH, Peterson PA, Wilson IA (1992) Emerging principles for the recognition of peptide antigens by MHC class I molecules. Science 257: 927-934.

12. Pamer E, Cresswell P (1998) Mechanisms of MHC class I-restricted antigen processing. Annu Rev Immunol 16: 323-358.

13. Craiu A, Akopian T, Goldberg A, Rock KL (1997) Two distinct proteolytic processes in the generation of a major histocompatibility complex class Ipresented peptide. Proc Natl Acad Sci U S A 94: 10850-10855.

14. Mo XY, Cascio P, Lemerise K, Goldberg AL, Rock K (1999) Distinct proteolytic processes generate the $\mathrm{C}$ and $\mathrm{N}$ termini of MHC class I-binding peptides. J Immunol 163: 5851-5859.

15. Abele R, Tampe R (1999) Function of the transport complex TAP in cellular immune recognition. Biochim Biophys Acta 1461: 405-419.

16. Hammond SA, Johnson RP, Kalams SA, Walker BD, Takiguchi M, et al. (1995) An epitope-selective, transporter associated with antigen presentation (TAP)-1/2-independent pathway and a more general TAP-1/2 dependent antigen-processing pathway allow recognition of the HIV-1 envelope glycoprotein by CD8 ${ }^{+}$CTL. J Immunol 154: 6140-6156.

17. Allen TM, Altfeld M, Yu XG, O'Sullivan KM, Lichterfeld M, et al. (2004) Selection, transmission, and reversion of an antigen-processing cytotoxic T-lymphocyte escape mutation in human immunodeficiency virus type 1 infection. J Virol 78: 7069-7078.

18. Niedermann G, Geier E, Lucchiari-Hartz M, Hitziger N, Ramsperger A, et al. (1999) The specificity of proteasomes: Impact on MHC class I processing and presentation of antigens. Immunol Rev 172: 29-48.

19. Daniel S, Brusic V, Caillat-Zucman S, Petrovsky N, Harrison L, et al. (1998) Relationship between peptide selectivities of human transporters associated with antigen processing and HLA class I molecules. J Immunol 161: $617-624$

20. Brusic V, Rudy G, Harrison LC (1998) MHCPEP, a database of MHCbinding peptides: Update 1997. Nucleic Acids Res 26: 368-371.

21. Bhasin M, Singh H, Raghava GP (2003) MHCBN: A comprehensive database of MHC binding and non-binding peptides. Bioinformatics 19: 665-666.

22. Peters B, Sidney J, Bourne P, Bui HH, Buus S, et al. (2005) The immune epitope database and analysis resource: From vision to blueprint. PLoS Biol 3: e91. DOI: 10.1371/journal.pbio.0030091

23. Marsh SGE, Parjam P, Barber LD (2000) The HLA factsbook. London: Academic Press. $416 \mathrm{p}$

24. Rammensee HG, Bachman J, Stevanovich S (1997) MHC ligands and peptide motifs. Georgetown: Landes Bioscience. pp. 1-462.

25. Sette A, Buus S, Appella E, Smith JA, Chesnut R, et al. (1989) Prediction of major histocompatibility complex binding regions of protein antigens by sequence pattern analysis. Proc Natl Acad Sci U S A 86: 3296-3300.

26. Nijman HW, Houbiers JG, Vierboom MP, van der Burg SH, Drijfhout JW, et al. (1993) Identification of peptide sequences that potentially trigger HLAA2.1-restricted cytotoxic T lymphocytes. Eur J Immunol 23: 1215-1219.

27. Buus S (1999) Description and prediction of peptide-MHC binding: The "human MHC project." Curr Opin Immunol 11: 209-213.

28. De Groot AS, Bosma A, Chinai N, Frost J, Jesdale BM, et al. (2001) From genome to vaccine: In silico predictions, ex vivo verification. Vaccine 19: 4385-4395.

29. De Groot AS, Marcon L, Bishop EA, Rivera D, Kutzler M, et al. (2005) HIV vaccine development by computer assisted design: The GAIA vaccine. Vaccine 23: 2136-2148.

30. Lauemoller SL, Holm A, Hilden J, Brunak S, Holst Nissen M, et al. (2001) Quantitative predictions of peptide binding to MHC class I molecules using specificity matrices and anchor-stratified calibrations. Tissue Antigens 57: 405-414.

31. Parker KC, Bednarek MA, Coligan JE (1994) Scheme for ranking potential HLA-A2 binding peptides based on independent binding of individual peptide side-chains. J Immunol 152: 163-175.

32. Brusic V, Bajic VB, Petrovsky N (2004) Computational methods for prediction of $\mathrm{T}$-cell epitopes-A framework for modelling, testing, and applications. Methods 34: 436-443.

33. Rammensee H, Bachmann J, Emmerich NP, Bachor OA, Stevanovic S (1999) SYFPEITHI: Database for MHC ligands and peptide motifs. Immunogenetics 50: 213-219.

34. Thakalapally R, Kibbe W, Lang D, Korber B, Korber B, et al. (2000) Motifscan: A Web-based tool to find HLA anchor residues in proteins or peptides. HIV Molecular Immunology Database 2000. Los Alamos: Theoretical Biology and Biophysics Group, Los Alamos National Laboratory. Publication number LA-UR 02-2877. pp. I-101.

35. Yusim KSJ,, Honeyborne I, Calef C, Goulder PJ, Korber BT (2004) Enhanced motif scan: A tool to scan for HLA anchor residues in proteins. HIV Immunology and HIVISIV Vaccine Databases 2003. Los Alamos: Theoretical Biology and Biophysics Group, Los Alamos National Laboratory. Publication number LA-UR 04-8162. pp. 25-36.

36. Calef C, Thakalapally R, Kaslow R, Mulligan M, Korber B, et al. (2001) ELF An analysis tool for HIV-1 peptides and HLA types. HIV Molecular Immunology 2001. Los Alamos: Theoretical Biology and Biophysics Group, Los Alamos National Laboratory. Publication number LA-UR 02-2877. pp. I-21.
37. Korber BT, Brander C, Haynes B, Koup R, Moore JP, et al. (2005) HIV molecular immunology 2005. Los Alamos: Theoretical Biology and Biophysics Group, Los Alamos National Laboratory. Publication number LA-UR 06-0036. pp. 1-1158. Available: http://www.hiv.lanl.gov/content/ immunology/index.html. Accessed 4 June 2006.

38. Yusim K, Richardson R, Tao N, Dalwani A, Agrawal A, et al. (2005) Los Alamos hepatitis C immunology database. Appl Bioinformatics 4: 217-225.

39. Leggatt GR, Hosmalin A, Pendleton CD, Kumar A, Hoffman S, et al. (1998) The importance of pairwise interactions between peptide residues in the delineation of TCR specificity. J Immunol 161: 4728-4735.

40. Bhasin M, Raghava GP (2004) Prediction of CTL epitopes using QM, SVM and ANN techniques. Vaccine 22: 3195-3204.

41. Bhasin M, Raghava GP (2004) Analysis and prediction of affinity of TAP binding peptides using cascade SVM. Protein Sci 13: 596-607.

42. Bhasin M, Raghava GP (2005) Pcleavage: An SVM based method for prediction of constitutive proteasome and immunoproteasome cleavage sites in antigenic sequences. Nucleic Acids Res 33: W202-W207.

43. Gulukota K, Sidney J, Sette A, DeLisi C (1997) Two complementary methods for predicting peptides binding major histocompatibility complex molecules. J Mol Biol 267: 1258-1267.

44. Kesmir C, Nussbaum AK, Schild H, Detours V, Brunak S (2002) Prediction of proteasome cleavage motifs by neural networks. Protein Eng 15: 287-296.

45. Kuttler C, Nussbaum AK, Dick TP, Rammensee HG, Schild H, et al. (2000) An algorithm for the prediction of proteasomal cleavages. J Mol Biol 298: $417-429$

46. Milik M, Sauer D, Brunmark AP, Yuan L, Vitiello A, et al. (1998) Application of an artificial neural network to predict specific class I MHC binding peptide sequences. Nat Biotechnol 16: 753-756.

47. Schonbach C, Kun Y, Brusic V (2002) Large-scale computational identification of HIV T-cell epitopes. Immunol Cell Biol 80: 300-306.

48. Yu K, Petrovsky N, Schonbach C, Koh JY, Brusic V (2002) Methods for prediction of peptide binding to MHC molecules: A comparative study. Mol Med 8: 137-148.

49. Lund O, Nielsen M, Kesmir C, Christensen JK, Lundegaard C, et al. (2002) Web-based tools for vaccine design. In: Korber BT, Brander C, Haynes BF, Koup R, Kuiken C, et al., editors. Los Alamos: Theoretical Biology and Biophysics Group, Los Alamos National Laboratory. pp. 48-55 Available: http://www.hiv.lanl.gov/content/hiv-db/REVIEWS/Lund2002.html.Accessed 4 June 2006

50. Guan P, Doytchinova IA, Zygouri C, Flower DR (2003) MHCPred: Bringing a quantitative dimension to the online prediction of MHC binding. Appl Bioinformatics 2: 63-66.

51. Guan P, Doytchinova IA, Zygouri C, Flower DR (2003) MHCPred: A server for quantitative prediction of peptide-MHC binding. Nucleic Acids Res 31: 3621-3624.

52. Altuvia Y, Sette A, Sidney J, Southwood S, Margalit H (1997) A structurebased algorithm to predict potential binding peptides to MHC molecules with hydrophobic binding pockets. Hum Immunol 58: 1-11.

53. Schueler-Furman O, Altuvia Y, Sette A, Margalit H (2000) Structure-based prediction of binding peptides to MHC class I molecules: Application to a broad range of MHC alleles. Protein Sci 9: 1838-1846.

54. Altuvia Y, Margalit H (2000) Sequence signals for generation of antigenic peptides by the proteasome: Implications for proteasomal cleavage mechanism. J Mol Biol 295: 879-890.

55. Parker KC, Shields M, DiBrino M, Brooks A, Coligan JE (1995) Peptide binding to $\mathrm{MHC}$ class I molecules: Implications for antigenic peptide prediction. Immunol Res 14: 34-57.

56. Hakenberg J, Nussbaum AK, Schild H, Rammensee HG, Kuttler C, et al. (2003) MAPPP: MHC class I antigenic peptide processing prediction. Appl Bioinformatics 2: 155-158.

57. Holzhutter HG, Frommel C, Kloetzel PM (1999) A theoretical approach towards the identification of cleavage-determining amino acid motifs of the $20 \mathrm{~S}$ proteasome. J Mol Biol 286: 1251-1265.

58. Holzhutter HG, Kloetzel PM (2000) A kinetic model of vertebrate $20 \mathrm{~S}$ proteasome accounting for the generation of major proteolytic fragments from oligomeric peptide substrates. Biophys J 79: 1196-1205.

59. Nielsen M, Lundegaard C, Lund O, Kesmir C (2005) The role of the proteasome in generating cytotoxic T-cell epitopes: Insights obtained from improved predictions of proteasomal cleavage. Immunogenetics 57: 33-41.

60. Buus S, Lauemoller SL, Worning P, Kesmir C, Frimurer T, et al. (2003) Sensitive quantitative predictions of peptide-MHC binding by a "Query by Committee" artificial neural network approach. Tissue Antigens 62: 378384.

61. Nielsen M, Lundegaard C, Worning P, Hvid CS, Lamberth K, et al. (2004) Improved prediction of MHC class I and class II epitopes using a novel Gibbs sampling approach. Bioinformatics 20: 1388-1397.

62. Nielsen M, Lundegaard C, Worning P, Lauemoller SL, Lamberth K, et al. (2003) Reliable prediction of T-cell epitopes using neural networks with novel sequence representations. Protein Sci 12: 1007-1017.

63. Lund O, Nielsen M, Kesmir C, Petersen AG, Lundegaard C, et al. (2004) Definition of supertypes for HLA molecules using clustering of specificity matrices. Immunogenetics 55: 797-810.

64. Sette A, Sidney J (1999) Nine major HLA class I supertypes account for the vast preponderance of HLA-A and -B polymorphism. Immunogenetics 50: 201-212. 
65. Peters B, Bulik S, Tampe R, Van Endert PM, Holzhutter HG (2003) Identifying MHC class I epitopes by predicting the TAP transport efficiency of epitope precursors. J Immunol 171: 1741-1749.

66. Saha S, Bhasin M, Raghava GP (2005) Bcipep: A database of B-cell epitopes. BMC Genomics 6: 79.

67. Singh H, Raghava GP (2001) ProPred: Prediction of HLA-DR binding sites Bioinformatics 17: 1236-1237.

68. Singh H, Raghava GP (2003) ProPred1: Prediction of promiscuous MHC class-I binding sites. Bioinformatics 19: 1009-1014.

69. Bhasin M, Raghava GP (2003) Prediction of promiscuous and high-affinity mutated MHC binders. Hybrid Hybridomics 22: 229-234.

70. Bui HH, Sidney J, Peters B, Sathiamurthy M, Sinichi A, et al. (2005) Automated generation and evaluation of specific MHC binding predictive tools: ARB matrix applications. Immunogenetics 57: 304-314.

71. Peters B, Sette A (2005) Generating quantitative models describing the sequence specificity of biological processes with the stabilized matrix method. BMC Bioinformatics 6: 132.

72. Tenzer S, Peters B, Bulik S, Schoor O, Lemmel C, et al. (2005) Modeling the MHC class I pathway by combining predictions of proteasomal cleavage, TAP transport and MHC class I binding. Cell Mol Life Sci 62: 1025-1037.

73. De Groot AS, Jesdale B, Martin W, Saint Aubin C, Sbai H, et al. (2003) Mapping cross-clade HIV-1 vaccine epitopes using a bioinformatics approach. Vaccine 21: 4486-4504.

74. Fonseca CT, Cunha-Neto E, Kalil J, Jesus AR, Correa-Oliveira R, et al. (2004) Identification of immunodominant epitopes of Schistosoma mansoni vaccine candidate antigens using human T cells. Mem Inst Oswaldo Cruz 99: 63-66.

75. Fischer W PS, Theiler J, Bhattacharya T, Yusim K, et al (2006) Designing polyvalent HIV-1 vaccines for optimal coverage of potential T-cell epitopes in diverse global variants. Nat Med. In press.

76. Robinson J, Waller MJ, Parham P, de Groot N, Bontrop R, et al. (2003) IMGT/HLA and IMGT/MHC: Sequence databases for the study of the major histocompatibility complex. Nucleic Acids Res 31: 311-314.

77. Wheeler DL, Barrett T, Benson DA, Bryant SH, Canese K, et al. (2006) Database resources of the National Center for Biotechnology Information. Nucleic Acids Res 34: D173-180.

78. Allcock RJ, Atrazhev AM, Beck S, de Jong PJ, Elliott JF, et al. (2002) The MHC haplotype project: A resource for HLA-linked association studies. Tissue Antigens 59: 520-521.

79. Traherne JA, Horton R, Roberts AN, Miretti MM, Hurles ME, et al. (2006) Genetic analysis of completely sequenced disease-associated MHC haplotypes identifies shuffling of segments in recent human history. PLoS Genet 2: e9. DOI: 10.1371/journal.pgen.0020009

80. Kiepiela P, Leslie AJ, Honeyborne I, Ramduth D, Thobakgale C, et al. (2004) Dominant influence of HLA-B in mediating the potential co-evolution of HIV and HLA. Nature 432: 769-775.

81. Calef C, Thakalapally R, Lang D, Brander C, Goulder P, et al. (2000) PeptGen: Designing peptides for immunological studies and application to HIV consensus sequences. In: Korber BT, Brander C, Haynes B, Koup R,
Moore JP, et al., editors. Los Alamos: Theoretical Biology and Biophysics Group, Los Alamos National Laboratory. pp. I-63.

82. McSparron H, Blythe MJ, Zygouri C, Doytchinova IA, Flower DR (2003) JenPep: A novel computational information resource for immunobiology and vaccinology. J Chem Inf Comput Sci 43: 1276-1287.

83. Blythe MJ, Flower DR (2005) Benchmarking B cell epitope prediction: Underperformance of existing methods. Protein Sci 14: 246-248.

84. Chou PY, Fasman GD (1978) Prediction of the secondary structure of proteins from their amino acid sequence. Adv Enzymol Relat Areas Mol Biol 47: 45-148.

85. Emini EA, Hughes JV, Perlow DS, Boger J (1985) Induction of hepatitis A virus-neutralizing antibody by a virus-specific synthetic peptide. J Virol 55 : 836-839.

86. Karplus PA, Schulz GE (1985) Prediction of chain flexibility in proteins-A tool for the selection of peptide antigens. Naturwissenschafren 72: 212213.

87. Parker JM, Guo D, Hodges RS (1986) New hydrophilicity scale derived from high-performance liquid chromatography peptide retention data: Correlation of predicted surface residues with antigenicity and X-rayderived accessible sites. Biochemistry 25: 5425-5432.

88. Kolaskar AS, Tongaonkar PC (1990) A semi-empirical method for prediction of antigenic determinants on protein antigens. FEBS Lett 276 : 172-174

89. Martin AC (1996) Accessing the Kabat antibody sequence database by computer. Proteins 25: 130-133.

90. Chen J, Anderson JB, DeWeese-Scott C, Fedorova ND, Geer LY, et al. (2003) MMDB: Entrez's 3D-structure database. Nucleic Acids Res 31: 474-477.

91. Allcorn LC, Martin AC (2002) SACS-Self-maintaining database of antibody crystal structure information. Bioinformatics 18: 175-181.

92. Lefranc MP (2004) IMGT-ONTOLOGY and IMGT databases, tools and Web resources for immunogenetics and immunoinformatics. Mol Immunol 40: $647-660$

93. Lefranc MP, Giudicelli V, Kaas Q, Duprat E, Jabado-Michaloud J, et al. (2005) IMGT, the international ImMunoGeneTics information system. Nucleic Acids Res 33: D593-D597.

94. Hanke T, McMichael AJ, Mwau M, Wee EG, Ceberej I, et al. (2002) Development of a DNA-MVA/HIVA vaccine for Kenya. Vaccine 20: 19951998.

95. Doria-Rose NA, Learn GH, Rodrigo AG, Nickle DC, Li F, et al. (2005) Human immunodeficiency virus type 1 subtype B ancestral envelope protein is functional and elicits neutralizing antibodies in rabbits similar to those elicited by a circulating subtype B envelope. J Virol 79: 11214-11224.

96. Gao F, Weaver EA, Lu Z, Li Y, Liao HX, et al. (2005) Antigenicity and immunogenicity of a synthetic human immunodeficiency virus type 1 group $\mathrm{m}$ consensus envelope glycoprotein. J Virol 79: 1154-1163.

97. Gaschen B, Taylor J, Yusim K, Foley B, Gao F, et al. (2002) Diversity considerations in HIV-1 vaccine selection. Science 296: 2354-2360. 